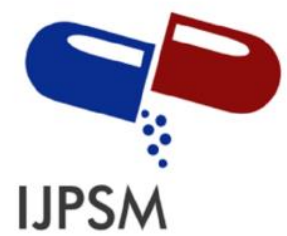

Kumrawat Kajal et al, International Journal of Pharmaceutical Sciences and Medicine (IJPSM), Vol.7 Issue. 1, January- 2022, pg. 1-23

ISSN: 2519-9889

Impact Factor: 5.365

\title{
Simultaneous Estimation of Sacubitril and Valsartan Combination of Drug in Tablet Dosage Form Using Hydrotropy by UV Spectrophotometry
}

\author{
Kumrawat Kajal $^{1}$; Tiwari Archana ${ }^{2}$ \\ ${ }^{1}$ Kumrawat Kajal, Swami Vivekanand College of Pharmacy, Khandwa Road, Indore, M.P., India \\ E-mail address: kajalkumrawat727@ gmail.com \\ ${ }^{2}$ Tiwari Archana, Swami Vivekanand College of Pharmacy, Khandwa Road, Indore, M.P., India \\ E-mail address: archanatiwari@ svcp.ac.in
}

DOI: 10.47760/ijpsm.2022.v07i01.001

\begin{abstract}
Sacubitril/valsartan, traded under the brand name Entresto between others, is a fixed-dose combination medication for use heart failure. Sacubitril is a neprilysin inhibitor (A prodrug) and is used in combination with valsartan to reduce the risk of cardiovascular events in patients with chronic heart failure. It is anti - hypertensive drug. Valsartan is an Angiotensin Receptor Blocker (ARB) that may be used to treat a variety of cardiac conditions including hypertension, diabetic nephropathy and heart failure. Two UV-spectrophotometric methods have been developed and validated for simultaneous estimation of Sacubitril and Valsartan in a tablet dosage form. The first method employed solving of simultaneous equations based on the measurement of absorbance at two wavelengths, $226.0 \mathrm{~nm}$ and $254.0 \mathrm{~nm}, \lambda \max$ for Sacubitril and Valsartan, respectively. The second method was absorbance ratio method, which involves formation of $Q$-absorbance equation at $240 \mathrm{~nm}$ (isoabsorptive point) and also at $254 \mathrm{~nm}$ ( $\lambda$ max of Valsartan). The methods were found to be linear between the range of $4-12 \mu \mathrm{g} / \mathrm{mL}$ for Sacubitril and 2-10 $\mu \mathrm{g} / \mathrm{mL}$ for Valsartan using Methanol as solvent. The mean percentage recovery was found to be $96.68 \%$ and $101.89 \%$ for the simultaneous equation method and $100.2 \%$ and $104.53 \%$ for the absorbance ratio method, for sacubitril and valsartan respectively. It could be concluded from the results obtained in the present investigation that the two methods for simultaneous estimation of sacubitril and valsartan in tablet dosage form are simple, rapid, accurate, precise and economical and can be used, successfully, in the quality control of pharmaceutical formulations and other routine laboratory analysis. The reviewed highlights various analytical techniques such as high-performance liquid chromatography (HPLC), ultraperformance liquid chromatography (UPLC), UV Spectroscopy, high per-formance thin layer chromatography (HPTLC), liquid chromatography coupled to tandem mass spectrometry (LC- MS), RP-HPLC and other chromatographic method used. The combination of these drugs with different method was examine and the commonly use of the drugs in hypertensive.
\end{abstract}

Keywords: Sacubitril, Valsartan, Distilled water, Methenol, Simultaneous Estimation, Hydrotropy H UV Spectrophotometry, ICH Guidelines 


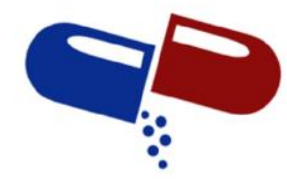

IJPSM

Kumrawat Kajal et al, International Journal of Pharmaceutical Sciences and Medicine (IJPSM), Vol.7 Issue. 1, January- 2022, pg. 1-23

ISSN: 2519-9889

Impact Factor: 5.365

\section{INTRODUCTION}

Analytical chemistry is a branch of science which is useful in various fields of science in pharmaceuticals and medicine due to its versatile application. It deals with two aspects of chemical analysis i.e. qualitative and quantitative analysis.

\section{Spectrophotometric method}

It is the bough of science commerce with the study of interaction between electromagnetic radiation and matter. It is a most powerful device available for the study of atomic and molecular structures and is used in the analysis of wide range of samples. Some of the commonly used Spectrophotometric methods are as follows,

- Simultaneous equation method (Vierdottes method)

- Derivative Spectrophotometric method

- $\quad$ Absorbance ratio method (Q-Absorbance method)

- Solvent extraction method

- Dual wavelength method

- Geometric correction method

- Orthogonal poly nominal method

- H-point standard addition method

- $\quad$ Least square approximation method

\section{- Simultaneous equation method}

If a sample contain two absorbing drugs (X \& Y) each of this absorbs at the $\lambda_{\max }$ of each other i.e. $\lambda_{1}$ and $\lambda_{2}$, it may be possible to determine both the drugs by the technique of simultaneous equation method provided that certain criteria apply. 


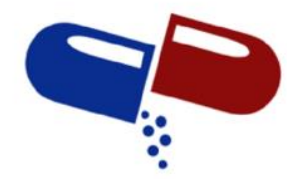

IJPSM

Kumrawat Kajal et al, International Journal of Pharmaceutical Sciences and Medicine (IJPSM), Vol.7 Issue. 1, January- 2022, pg. 1-23

ISSN: 2519-9889

Impact Factor: 5.365

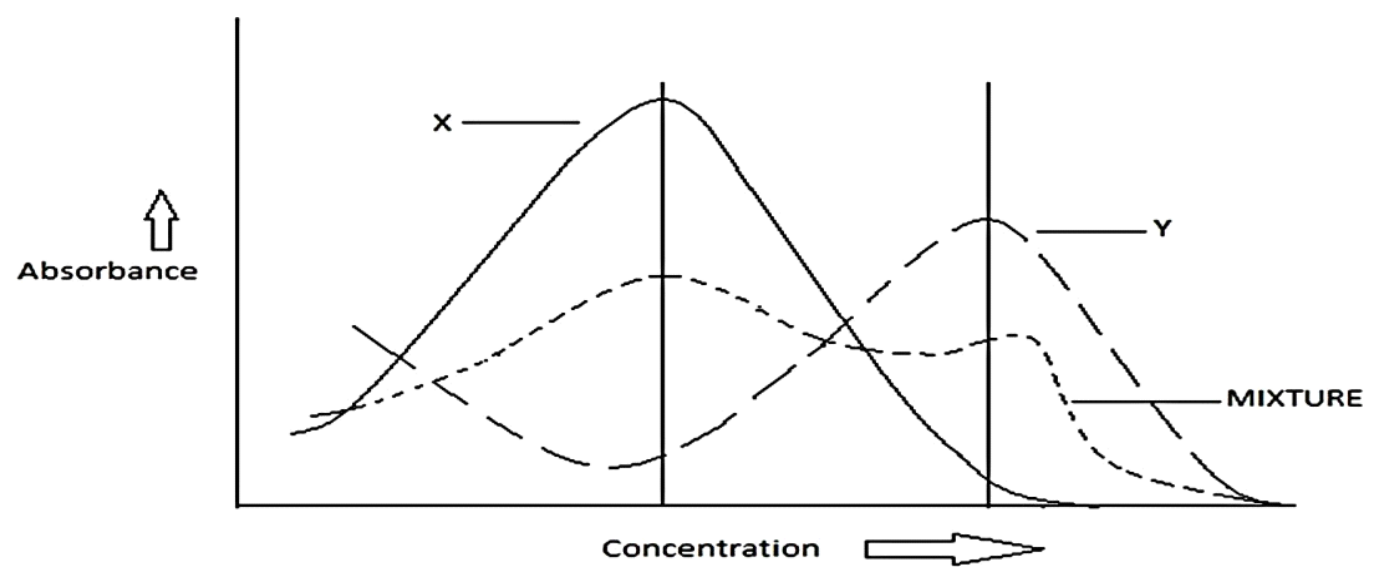

Figure 1: Overtone spectra of substance $\mathrm{X}$ and $\mathrm{Y}$

- The information required is:

- The absorptivity of $X$ at $\lambda_{1}$ and $\lambda_{2}$ and $\mathrm{ax}_{1}$ and $\mathrm{ax}_{2}$ respectively.

- The absorptivity of $Y$ at $\lambda_{1}$ and $\lambda_{2}$ and ay $y_{1}$ and ay ${ }_{2}$ respectively.

- The absorbance of the diluted sample at $\lambda_{1}$ and $\lambda_{2}, \mathrm{~A}_{1}$ and $\mathrm{A}_{2}$ respectively.

- Let $C_{x} \& C_{y}$ be the concentration of $X \& Y$ respectively in the diluted sample. Two equations are constructed based upon the fact that at $\lambda_{1}$ and $\lambda_{2}$ the absorbance of the mixture is the sum of the individual absorbance of $X \& Y$.

At

At

On rearranging equation (2)

$$
\mathrm{cy}=\mathrm{A} 2-\mathrm{ax} 2 \mathrm{cx} / \mathrm{ay} 2
$$

Substitution in equation (1) and rearranging, gives:

$$
\mathrm{cx}=\mathrm{A} 2 \mathrm{ay} 1-\mathrm{A} 1 \mathrm{ay} 2 / \mathrm{ax} 2 \mathrm{ay} 1-\mathrm{ax} 1 \mathrm{ay} 2
$$

And

$$
\mathrm{cy}=\mathrm{A} 1 \mathrm{ax} 2-\mathrm{A} 2 \mathrm{ax} 1 / \mathrm{ax} 2 \mathrm{ay} 1-\mathrm{ax} 1 \mathrm{ay} 2
$$

The ratios are:

$$
\mathrm{A} 2 / \mathrm{A} 1 / \mathrm{ax} 2 \mathrm{ax} 1 \& \text { ay2/ay1/A2/A1 }
$$

there is using two equations the concentration of component $\mathrm{X}$ and component $\mathrm{Y}$ in the mixture of sample which can be determined. 


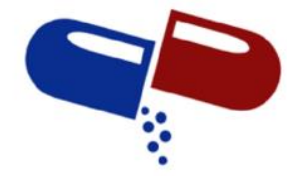

IJPSM

\section{Kumrawat Kajal et al, International Journal of Pharmaceutical Sciences and Medicine (IJPSM), Vol.7 Issue. 1, January- 2022, pg. 1-23}

ISSN: 2519-9889

Impact Factor: 5.365

\section{- Hydrotropy Theory}

Hydrotropy is the term discovered by „Carl A. Neuberge in 1916. Now days the hydrotropic solution possess high industrial demand due to their exclusive features like better solubility, absence of fire hazards, good recovery and fast separation feature without any emulsification problem. It produces eco-friendly nature and effective water solubility. It involves the watersoluble or water-insoluble categories. Most of the newly developed drug molecules are lipophilic in nature and pitiable solubility is the most difficult problems of these drugs. Drug analysis in final product is important step. There are available some organic solvents such as methanol, chloroform, dimethylformamide and acetonitrile have been employed for solubilization of poorly water-soluble drugs to carry out analysis of poorly water-soluble drugs Hydrotropic solubilization is based on analytical method (5). The process is mainly related to quantitative term which is defined as the concentration of the solute in a saturated solution at a certain temperature, and in qualitative terms is defined as the spontaneous interaction of two or more substances to form a homogeneous molecular dispersion. The solubility of the drug may be expressed as parts, percentage, molarity, molality, volume fraction and mole fraction.

Table 1: Expression for approximate solubility

\begin{tabular}{|c|c|}
\hline Descriptive terms & Relative amounts of solvents to dissolve 1 part of solute \\
\hline Very soluble & Less than 1 \\
\hline Freely soluble & From $1-10$ \\
\hline Soluble & From $10-30$ \\
\hline Sparingly soluble & From $30-100$ \\
\hline Slightly soluble & From $100-1000$ \\
\hline Very soluble & From $1000-10,000$ \\
\hline Insoluble or practically insoluble & More than 10,000 \\
\hline
\end{tabular}

Hydrotropy solubilisation is process of addition of a large amount of the second solute results which increase in the aqueous solubility of another solute. There are generally consist of two hydrotropic salts known as, anionic part and hydrotropic aromatic ring. It contains the ionic organic salts, which increase the solubility in the solvent are "salt in" and those salts which decrease solubility are "salt out" solute.

Many solvents have large anion and cation which is completely solubilize in water called Hydrotropic salts.

This phenomenon known as "hydrotropism". It does not show colloidal properties (6). 


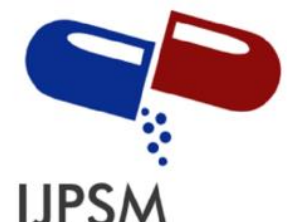

Kumrawat Kajal et al, International Journal of Pharmaceutical Sciences and Medicine (IJPSM), Vol.7 Issue. 1, January- 2022, pg. 1-23

ISSN: 2519-9889

Impact Factor: 5.365

Characteristics of Hydrotropes-

- Completely soluble in water and practically insoluble in the system.

- Hydrotropes are surface active and aggregate in aqueous solution because of their amphiphilic structure.

- Should not produce any temperature when dissolved in water.

- Cheap and easy availability.

- Nontoxic and non-reactive.

- Insensitive to temperature effects, when dissolved in water.

- The solvent character being independent of $\mathrm{pH}$, high selectivity, and the absence of emulsification are the other unique advantages of the hydrotrope.

\section{Advantages of Hydrotropic Solubilization}

- Hydrotropy is suggested to be superior to other solubilization methods, such immiscibility, micellar solubilization, cosolvency and salting in, because the solvent characteristics are independent of $\mathrm{pH}$, and have high selectivity and does not require emulsification.

- It only requires mixing the drug with the hydrotrope in water.

- It does not require chemical modification of hydrophobic drugs, use of organic solvents, or preparation of emulsion system (7).

\section{- DRUG PROFILE}

In the proposed study an attempt will be made to develop a HPLC method for simultaneous estimation of Sacubitril and Valsartan (9). This new drug was discovered and developed as tablet dosage form called ENTRESTO by Novartis, which was then approved by US Food and Drug Administration (FDA) in July 2015 for the treatment of heart failure. ENTRESTO is a combined dosage form which contain sacubitril (SAC), a prodrug that results in neprilysin inhibition and

valsartan (VAL) which is angiotensin II Type-1 receptor blocker), is the first medicine in this category. This combined drug (previously known as LCZ696) is also a useful antihypertensive drug (10). Sacubitril or Valsartan is a first-in-class angiotensin receptor- neprilysin inhibitor (ARNi) approved for the treatment of HF. 


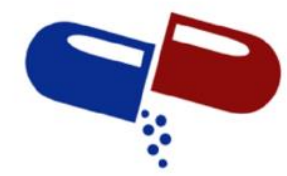

IJPSM

Kumrawat Kajal et al, International Journal of Pharmaceutical Sciences and Medicine (IJPSM), Vol.7 Issue. 1, January- 2022, pg. 1-23

ISSN: 2519-9889

Impact Factor: 5.365

\section{- Valsartan}

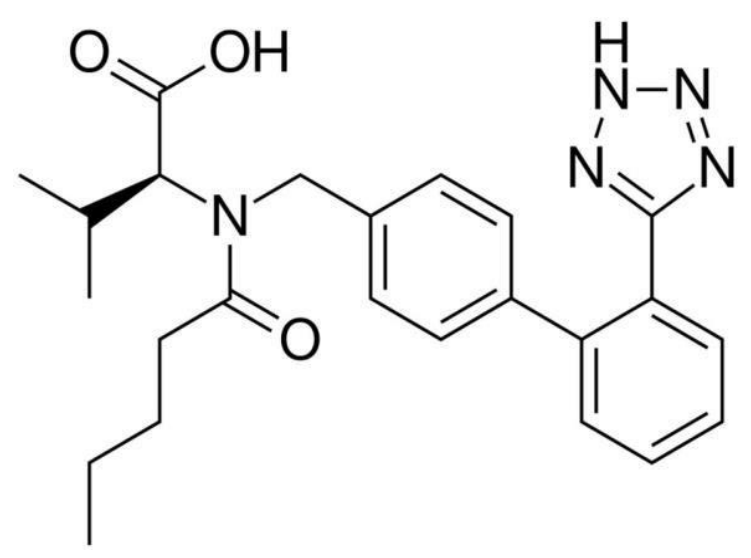

Figure 2: Chemical structure of valsartan

Valsartan is a tetrazole derivative; (2S)-3-methyl-2-[pentanoyl-[[4-[2-(2H-tetrazol-5-yl) phenyl] phenyl] methyl] amino] butanoic acid with molecular formula C24H29N5O3...chemical structure is shown in figure.

History of Valsartan- VAL was first developed by Novartis and was sold under the brand name DIOVAN. It is also available in combination with other antihypertensive drugs.

Physiological properties of valsartan: Valsartan is a white coloured powder that is freely soluble in ethanol, methanol and acetonitrile and sparingly soluble in water. Valsartan appears in the melting range of $105-110^{\circ} \mathrm{C}$ and the specific rotation [ $\alpha$ ] $\mathrm{D} / 20$ in methanol being $68^{\circ}$. The partition coefficient of Valsartan is 0.033 ( $\log \mathrm{P}=1.499$ ), suggesting that the compound is hydrophilic at physiological $\mathrm{pH}$. The compound is stable under storage in dry conditions VAL is soluble in the neutral $\mathrm{pH}$ range (11).

\section{- Sacubitril}

Sacubitril is chemically designated as 4-\{[(2S,4R)-1-(4-Biphenylyl)-5-ethoxy-4-methyl-5oxo-2-pentanyl]amino $\}-4-$ oxobutanoic acid. Its molecular formula is $\mathrm{C} 24 \mathrm{H} 29 \mathrm{NO}$, and its molecular weight is $411.49 \mathrm{~g} / \mathrm{mol}$ (11). 


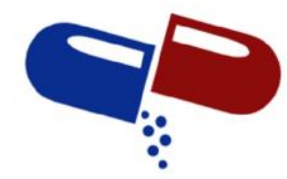

IJPSM

Kumrawat Kajal et al, International Journal of Pharmaceutical Sciences and Medicine (IJPSM), Vol.7 Issue. 1, January- 2022, pg. 1-23

ISSN: 2519-9889

Impact Factor: 5.365

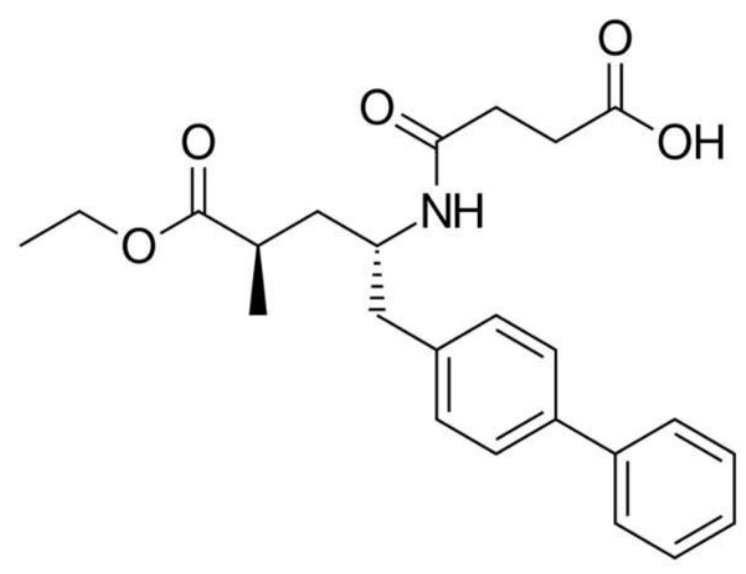

Figure 3: Chemical Structure of Sacubitril

Sacubitril is a neprilysin inhibitor and is used in combination with valsartan to reduce the risk of cardiovascular events in patients with chronic heart failure (NYHA Class II-IV). The combination drug, sacubitril/valsartan is used in place of an ACE inhibitor or ARB. It was approved under the FDA ${ }^{\text {ee }}$ p priority review process for use in heart failure on July 7, 2015

$\{8\}$.

Physical and chemical properties of both drugs Sacubitril/Valsartan complex comprises of anionic forms of sacubitril and valsartan, sodium cations, and water molecules in the molar ratio of 1:1:3:2.5, respectively. A single complex consists of 6 valsartan anions, 6 sacubitril anions, 18 sodium cations, and 15 molecules of water, resulting in the molecular formula C288H330N36Na18O48_15H2O and a molecular mass of $5748.03 \mathrm{~g} / \mathrm{mol} .6,13$ The substance is a white powder consisting of thin hexagonal plates. It is stable in solid form as well as in aqueous (watery) solution with a pH of 5 to 7 , and a melting point of about $138 \mathrm{C}(280 \mathrm{~F})(12)$.

The main uses of both drugs are valsartanis used in Hypertensive, diabetic nephopathy and heart failure and sacubitril is used as antihypertensive drug and it is a prodrug which used in combination with valsartan.

\section{MATERIAL \& METHOD}

\section{The Instrument}

The instrument used for all analysis was the ANALYTIK JENA- SPECORD 210 PLUS spectrophotometer recording.

\section{Instpecrumental modes}

1)Photometric mode

2)Spectrum mode

3)Quantitation mode

4)Kinetics mode

5)Time scan mode 


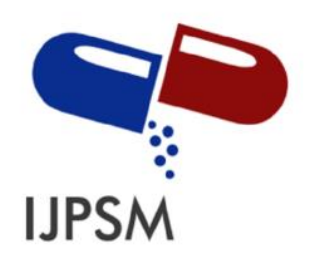

Kumrawat Kajal et al, International Journal of Pharmaceutical Sciences and Medicine (IJPSM), Vol.7 Issue. 1, January- 2022, pg. 1-23

ISSN: 2519-9889

Impact Factor: 5.365

6)Multi component

7)Multi wavelength mode

8)Utilities mode

MATERIAL

Selection of Drug

SACUBITRIL and VALSARTAN are two drugs which were selected for work after Literature survey the previous study reveals that there are reported work on Sacubitril and Valsartan on UV and HPLC but no work is reported on simultaneous as well as on absorbance method.

\section{Selection of Solvent}

Methanol: Water (60:40) was selected as the solvent after considering the solubility and stability factor of both the drugs as well as the interference due to excipient matrix present in the tablet formulation

\section{METHODOLOGY}

METHOD - I

\section{SIMULTANEOUS ESTIMATION OF SACUBITRIL AND VALSARTAN IN TABLET DOSAGE FORM BY USING SIMULTANEOUS EQUATIONS METHOD}

\section{Preparation of Standard Stock Solutions of SAC and VAL:}

$100 \mathrm{mg}$ of Sacubitril (SAC) and $100 \mathrm{mg}$ of Valsartan (VAL) were independently measured and transferred to two $100 \mathrm{ml}$ volumetric bottles. Each drug was dissolved in $60 \mathrm{ml}$ of methanol and shaken by hand for 10 minutes. The volume was formed by marking with water and the final available energy was $1000 \mu \mathrm{g} / \mathrm{ml}$.

\section{Determination of $\lambda$ max:}

From the stock solutions, $.1 \mathrm{ml}$ of SAC and $.1 \mathrm{ml}$ of VAL was transferred to two separate $10 \mathrm{ml}$ volumetric flasks and the volume was adjusted to the mark with solvent i.e. strength obtained was $10 \mu \mathrm{g} / \mathrm{ml}$ for SAC and $10 \mu \mathrm{g} / \mathrm{ml}$ for VAL. Both the drug solutions were scanned separately between $200 \mathrm{~nm}$ to $400 \mathrm{~nm}$. The overlain spectrum of both drugs was recorded (Shown in Fig 3) and two wavelengths $226.0 \mathrm{~nm}(\lambda \max$ of SAC) $\mathrm{nm}$ and $254.0 \mathrm{~nm}$ ( $\lambda$ max of VAL) were selected for estimation of drugs using simultaneous equation method. 


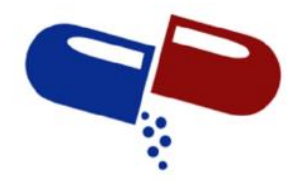

IJPSM

Kumrawat Kajal et al, International Journal of Pharmaceutical Sciences and Medicine (IJPSM), Vol.7 Issue. 1, January- 2022, pg. 1-23

ISSN: 2519-9889

Impact Factor: 5.365

\section{Study of Linearity for SAC:}

Appropriate known volumes of aliquots from standard SAC stock solution were transferred to five separate $10 \mathrm{ml}$ volumetric flasks. The volume was adjusted to the mark with Solvent to obtain concentrations of 4, 6, 8, 10, and 12; $\mu \mathrm{g} / \mathrm{ml}$. Absorbance's of these solutions were recorded at $226.0 \mathrm{~nm}$ and $254 \mathrm{~nm}$. (Shown in Table 1 and Table 2) and Calibration curve was plotted, absorbance $v s$ concentration (shown in Fig. 4 and Fig 5).

Table No: 1. Linearity study of SAC at $226.0 \mathrm{~nm}$

\begin{tabular}{|c|c|c|c|}
\hline Sr.No. & \begin{tabular}{l}
\multicolumn{2}{l}{ Concentration } \\
SAC in $\quad(\mu \mathrm{g} / \mathrm{ml})$
\end{tabular} & $\begin{array}{l}\text { Absorbance Mean } \\
\text { SD } \quad(n=5)\end{array}$ & $\%$ RSD \\
\hline 1 & 4 & $0.167 \pm 0.0015$ & 0.95 \\
\hline 2 & 6 & $0.252 \pm 0.0016$ & 0.65 \\
\hline 3 & 8 & $0.344 \pm 0.0016$ & 0.49 \\
\hline 4 & 10 & $0.418 \pm 0.0017$ & 0.39 \\
\hline 5 & 12 & $0.510 \pm 0.0015$ & 0.30 \\
\hline
\end{tabular}

Table No: 2. Linearity study of SAC at $254.0 \mathrm{~nm}$.

\begin{tabular}{|l|ll|l|l|}
\hline Sr.No. & \multicolumn{2}{|c|}{$\begin{array}{l}\text { Concentration } \\
\text { SAC in }(\mu \mathrm{g} / \mathrm{ml})\end{array}$} & $\begin{array}{c}\text { Absorbance Mean } \\
\pm \mathrm{SD} \quad(\mathrm{n}=5)\end{array}$ & $\%$ RSD \\
\hline 1 & 4 & $0.160 \pm 0.0013$ & 0.80 \\
\hline 2 & 6 & $0.242 \pm 0.0011$ & 0.47 \\
\hline 3 & 8 & $0.324 \pm 0.0011$ & 0.35 \\
\hline 4 & 10 & $0.400 \pm 0.0012$ & 0.28 \\
\hline 5 & 12 & $0.483 \pm 0.0013$ & 0.27 \\
\hline
\end{tabular}

\section{Study of Linearity for VAL:}

Appropriate known volumes of aliquots from standard VAL stock solution were transferred to five separate $10 \mathrm{ml}$ volumetric flasks. The volume was adjusted to the mark with Solvent to obtain concentrations of 2, 4, 6, 8 and 10 $\mu \mathrm{g} / \mathrm{ml}$. Absorbance of these solutions were measured at $226 \mathrm{~nm}$ and $254.0 \mathrm{~nm}$. (Table 3 an Table 4) and the calibration curve were plotted, absorbance $V s$ concentration (shown in Fig. 6 and Fig. 7) 


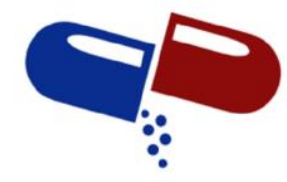

IJPSM

Kumrawat Kajal et al, International Journal of Pharmaceutical Sciences and Medicine (IJPSM), Vol.7 Issue. 1, January- 2022, pg. 1-23

ISSN: 2519-9889

Impact Factor: 5.365

Table No: 3. Linearity study of VAL at $226.0 \mathrm{~nm}$.

\begin{tabular}{|c|c|c|c|}
\hline \multirow[t]{2}{*}{ Sr.No. } & $\begin{array}{ll}\text { Concentration } & 0\end{array}$ & Absorbance Mean & \multirow[t]{2}{*}{ \% RSD } \\
\hline & VAL in $\quad(\mu \mathrm{g} / \mathrm{ml})$ & \pm SD & \\
\hline 1 & 2 & $0.092 \pm 0.0015$ & 1.71 \\
\hline 2 & 4 & $0.184 \pm 0.0015$ & 0.85 \\
\hline 3 & 6 & $0.240 \pm 0.0015$ & 0.57 \\
\hline 4 & 8 & $\mathbf{0 . 3 6 3} \pm 0.0015$ & 0.43 \\
\hline 5 & 10 & $0.457 \pm 0.0016$ & 0.33 \\
\hline
\end{tabular}

Table No: 4. Linearity study of VAL at $254.0 \mathrm{~nm}$

\begin{tabular}{|c|c|c|c|}
\hline Sr.No. & Concentration of & Absorbance Mean & \% RSD \\
\hline & VAL in $\quad(\mu \mathrm{g} / \mathrm{ml})$ & $\pm \mathrm{SD} \quad(\mathrm{n}=5)$ & \\
\hline 1 & 2 & $0.224 \pm 0.0020$ & 0.92 \\
\hline 2 & 4 & $0.448 \pm 0.0019$ & 0.43 \\
\hline 3 & 6 & $0.672 \pm 0.0020$ & 0.30 \\
\hline 4 & 8 & $0.889 \pm 0.0019$ & 0.21 \\
\hline 5 & 10 & $1.099 \pm 0.0019$ & 0.17 \\
\hline
\end{tabular}

Determination of Absorptivity values of drugs at selected wavelengths:

Absorptivity values of SAC and VAL were calculated by using following formula :- a $(1 \%, 1 \mathrm{~cm})=\mathrm{A} / \mathrm{C}$

$\mathrm{L}$

Where, $\mathrm{a}=$ absorptivity, $\mathrm{A}=$ absorbance,

$$
\begin{aligned}
\mathrm{C} & =\text { concentration } \mathrm{gm} / 100 \mathrm{ml}, \\
\mathrm{L} & =\text { path length }
\end{aligned}
$$

Results of absorptivity values of drugs are shown in Table 5. 


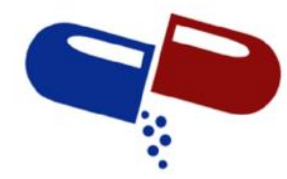

IJPSM

Kumrawat Kajal et al, International Journal of Pharmaceutical Sciences and Medicine (IJPSM), Vol.7 Issue. 1, January- 2022, pg. 1-23

ISSN: 2519-9889

Impact Factor: 5.365

Table No: 5. Absorptivity Values of SAC and VAL at $226.0 \mathrm{~nm}$ and $254.0 \mathrm{~nm}$

\begin{tabular}{|l|l|l|l|l|}
\hline \multirow{2}{*}{ Sr.No. } & \multicolumn{2}{|l|}{ Absorptivity at $\mathbf{2 2 6 . 0} \mathbf{~ n m}$} & \multicolumn{2}{c|}{ Absorptivity at 254.0 nm } \\
\hline & SAC & VAL & SAC & VAL \\
\hline $\mathbf{1}$ & 417.5 & 460.0 & 400.0 & 1120.0 \\
\hline $\mathbf{2}$ & 420.0 & 457.5 & 403.3 & 1120.0 \\
\hline $\mathbf{3}$ & 417.5 & 458.33 & 405.0 & 1120.0 \\
\hline $\mathbf{4}$ & 418.0 & 456.25 & 409.0 & 1111.25 \\
\hline $\mathbf{5}$ & 425.0 & 457.0 & 402.5 & 1099.0 \\
\hline Mean & $\mathbf{a x 1 = 4 1 9 . 6 6}$ & $\mathbf{a x 2 = 4 5 8 . 3 1}$ & $\mathbf{a y 1}=404.13$ & $\mathbf{a y 2}=1107.40$ \\
\hline
\end{tabular}

A set of two simultaneous equations were framed using these absorptivity coefficient values are given below.

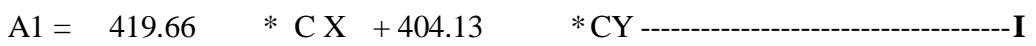

$$
\begin{aligned}
& \mathrm{A} 2=458.31 \quad * \mathrm{CX}+1107.40 \quad * \mathrm{CY}
\end{aligned}
$$

Where, CX and CY are the concentrations of SAC and VAL, respectively in grams per $100 \mathrm{~mL}$ in the sample solution.

$\mathbf{A 1}$ and $\mathbf{A 2}$ are the absorbance of the sample solution measured at $226.0 \mathrm{~nm}$ and $254.0 \mathrm{~nm}$, respectively.

By rearranging equations I and II.

Concentrations $\mathbf{C X}$ and $\mathbf{C Y}$ can be obtained as:

$\mathrm{A} 2 \times 458.31-\mathrm{A} 1 \times \mathbf{1 1 0 7 . 4 0}$

$\mathrm{CX}=$

III

$-279514.6637$

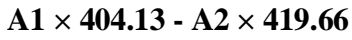

CY =

IV

$-279514.6637$ 


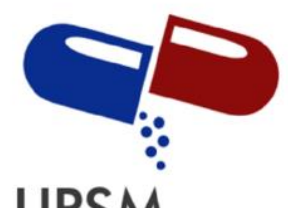

Kumrawat Kajal et al, International Journal of Pharmaceutical Sciences and Medicine (IJPSM), Vol.7 Issue. 1, January- 2022, pg. 1-23

ISSN: 2519-9889

Impact Factor: 5.365

\section{- Laboratory mixture analysis by proposed method:}

In order to demonstrate the concurrence of the proposed simultaneous evaluation of SAC and VAL in the development of manufactured drugs, this approach was first attempted to balance drugs in a standard laboratory association.

A well-balanced dose of $100 \mathrm{mg}$ SAC and $100 \mathrm{mg}$ VAL was taken in a $100 \mathrm{ml}$ volumetric bottle and dissolved in 60 $\mathrm{ml}$ of Methanol by vigorous shaking. The volume is built into the marker with distilled water. The aliquot portions of this stock solution were further diluted with solvent to get final concentration of SAC and VAL in ratio 4:8 and 6:6 $1 / 4 \mathrm{~g} / \mathrm{ml}$ respectively and the absorbance were measured at $226.0 \mathrm{~nm}$ and $254.0 \mathrm{~nm}$ against solvent as blank. Amount of each drug was estimated using III, IV equation as follows and results are reported in Table 6.

Table 6: Analysis of SAC and VAL in laboratory mixture:

\begin{tabular}{|l|l|l|l|l|l|}
\hline Sr.No. & $\begin{array}{l}\text { Amount Taken } \\
\mathrm{mg} / \mathrm{mL}\end{array}$ & $\begin{array}{l}\text { Amount found } \\
\mathrm{mg} / \mathrm{mL}\end{array}$ & Amount found (\%) & SD & $\begin{array}{c}\% \\
\text { RSD }\end{array}$ \\
\hline 1 & SAC 4 & 4.04 & 101 & $\mathbf{0 . 0 0 1 6}$ & $\mathbf{0 . 3 0}$ \\
\hline 2 & VAL 8 & 7.96 & 99.67 & $\mathbf{0 . 0 0 0 8}$ & $\mathbf{0 . 0 7}$ \\
\hline 3 & SAC 6 & 6.17 & 102.98 & $\mathbf{0 . 0 0 0 8}$ & $\mathbf{0 . 1 4}$ \\
\hline 4 & VAL 6 & 6.23 & 103.88 & $\mathbf{0 . 0 0 1 6}$ & $\mathbf{0 . 1 7}$ \\
\hline
\end{tabular}

* No. of three estimations

\section{- Application of Proposed Method For Analysis of tablet Formulation :}

Twenty tablets were weighed and crushed to obtain a fine powder. An accurately weighed sample equivalent to 100 $\mathrm{mg}$ of SAC and $100 \mathrm{mg}$ of VAL was taken in a stoppered volumetric flask $(100.0 \mathrm{ml}) ; 60 \mathrm{ml}$ of Methanol was added and sonicated for $10 \mathrm{~min}$. The solution is filtered through Whatmann's filter paper (No. 41) and the volume is marked with the same water included. The aliquot components of the above solutions were then diluted with a solvent to obtain a final concentration of about $6(\mathrm{~g} / \mathrm{ml} \mathrm{SAC}$ and $6(\mathrm{~g} / \mathrm{ml} \mathrm{VAL}$, respectively and the reductions were measured at 226.0 $\mathrm{nm}$ and $254.0 \mathrm{~nm}$ in the negative. the drugs in the sample were determined using figures 3 and 4 . The results are reported in Table 7 


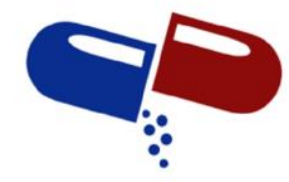

IJPSM

Kumrawat Kajal et al, International Journal of Pharmaceutical Sciences and Medicine (IJPSM), Vol.7 Issue. 1, January- 2022, pg. 1-23

ISSN: 2519-9889

Impact Factor: 5.365

Table 7: Application of Proposed Method for Analysis of Tablets

\begin{tabular}{|c|l|c|c|c|}
\hline Sample & Label claimed & \% Label claim $^{*}$ & $\mathbf{\pm}$ S.D & \% RSD \\
\hline \multirow{2}{*}{1} & SAC 24mg & 97.00 & .0016 & 0.31 \\
& VAL 26mg & 102.20 & .0024 & 0.26 \\
\hline
\end{tabular}

*Mean of three observations

- Validation of Proposed method:

- The Proposed method was validated as per the ICH guidelines.

- Accuracy :

- To assess the accuracy of the improved methods and to study the deformity of structural additives, the analytical recovery tests are performed in a standard add-on. The recovery study was performed by adding 80,100 and $120 \%$ of the test torture according to the ICH guidelines. The known amount of drug added to the preanalyzed tablet powder $6 \mu \mathrm{g}$ / $\mathrm{ml}$ of SAC and $6 \mu \mathrm{g} / \mathrm{ml}$ of VAL and the percentage return is calculated. The results and statistics for SAC and VAL are reported in Table 8.

Table 8: Recovery Study Data

\begin{tabular}{|l|l|c|l|l|}
\hline Sr.No. & \multicolumn{2}{|l|}{ Concentration of Drug Added $(\boldsymbol{\mu g} / \mathbf{m L})$} & \% Recovery \pm SD \\
\hline & SAC & VAL & SAC & VAL \\
\hline $\mathbf{1}$ & 4.8 & 4.8 & $97.22 \pm 0.16$ & $101.89 \pm 0.16$ \\
\hline $\mathbf{2}$ & 6.0 & 6.0 & $97.16 \pm 0.08$ & $101.95 \pm 0.16$ \\
\hline $\mathbf{3}$ & 7.2 & 7.2 & $96.68 \pm 0.08$ & $102.22 \pm 0.08$ \\
\hline
\end{tabular}

* Mean of three observations

\section{- Precision:}

- Precision is determined by intra-day and inter-day precision. Intra-day precision was determined by analyzing the 4,6 , $8,1 / 4 \mathrm{~g} / \mathrm{mL}$ of SAC and $2,4,61 / 4 \mathrm{~g} / \mathrm{mL}$ of VAL of drug solutions for three times in the same day. Inter-day precision was determined by analyzing the $4,6,8,1 / 4 \mathrm{~g} / \mathrm{mL}$ of SAC and 2, 4, $61 / 4 \mathrm{~g} / \mathrm{mL}$ of VAL of drug solutions daily for three days, results are reported in Table 9. 


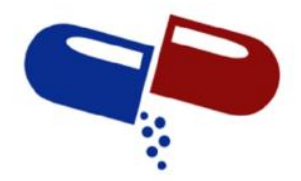

IJPSM

Kumrawat Kajal et al, International Journal of Pharmaceutical Sciences and Medicine (IJPSM), Vol.7 Issue. 1, January- 2022, pg. 1-23

ISSN: 2519-9889

Impact Factor: 5.365

Table 9: Intraday and Interday precision

\begin{tabular}{|l|l|l|l|l|l|l|}
\hline SR.NO & Drug & Conc. & Intraday* & \%RSD & Interday * & \%RSD \\
\hline & & $4.0 \mu \mathrm{g} / \mathrm{ml}$ & 4.05 & 0.48 & 3.98 & 0.98 \\
\hline $\mathbf{1}$ & SAC & $6.0 \mu \mathrm{g} / \mathrm{ml}$ & 5.97 & 0.65 & 6.07 & 0.64 \\
\hline & & $8.0 \mu \mathrm{g} / \mathrm{ml}$ & 7.97 & 0.48 & 8.04 & 0.48 \\
\hline \multirow{2}{*}{} & & $2.0 \mu \mathrm{g} / \mathrm{ml}$ & 2.01 & 0.36 & 1.92 & 0.74 \\
\hline & VAL & $4.0 \mu \mathrm{g} / \mathrm{ml}$ & 3.98 & 0.36 & 4.02 & 0.36 \\
\hline & & $6.0 \mu \mathrm{g} / \mathrm{ml}$ & 6.03 & 0.24 & 6.07 & 0.25 \\
\hline
\end{tabular}

*Mean of three observations

\section{- Repeatability:}

Repeatability was determined by analyzing SAC (6 1/4g/mL) and VAL (6 1/4g/mL) concentration of drug solutions for five times and results are reported in Table 10

Table 10: Repeatability data

\begin{tabular}{|l|l|l|l|l|}
\hline Sr.No & Drug & $\begin{array}{l}\text { Amount taken* } \\
(\boldsymbol{\mu g} / \mathbf{m L})\end{array}$ & $\begin{array}{l}\text { Amount found } \\
(\boldsymbol{\mu g} / \mathbf{m L})\end{array}$ & \% RSD \\
\hline 1 & SAC & 6 & 5.97 & 0.65 \\
\hline 2 & VAL & 6 & 6.05 & 0.30 \\
\hline
\end{tabular}

*Mean of five observation

\section{- Ruggedness:}

Ruggedness of the proposed method is determined by analysis of aliquots from homogenous slot by two analyst using same operational and environmental conditions and the results are reported in Table $\mathbf{1 1}$

Table 11: Ruggedness Data

\begin{tabular}{|l|l|l|l|l|l|}
\hline Drug & Amount taken $(\mu \mathrm{g} / \mathrm{ml})$ & Analyst I* & \%RSD & Analyst II * & \% RSD \\
\hline SAC & 6.0 & 5.97 & 0.65 & 6.16 & 0.61 \\
\hline VAL & 6.0 & 6.05 & 0.30 & 6.25 & 0.23 \\
\hline
\end{tabular}

*Mean of five estimation 


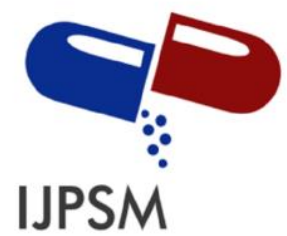

Kumrawat Kajal et al, International Journal of Pharmaceutical Sciences and Medicine (IJPSM), Vol.7 Issue. 1, January- 2022, pg. 1-23

ISSN: 2519-9889

Impact Factor: 5.365

\section{- $\quad$ Linearity}

For each drug, appriote dilutions of standard stock solution were assayed as per the developed method. The Beer s Lambert s concentration range was found to be $4-20 \mathrm{mg} / \mathrm{ml}$ for SAC and $2-10 \mathrm{mg} / \mathrm{ml}$ for VAL at their respective selected wavelengths. Coefficient of correlation was found to be 0.9996 for SAC and 0.9998 for VAL.

\section{METHOD II}

\section{SIMULTANEOUS ESTIMATION OF SACUBITRIL AND VALSARTAN IN TABLET DOSAGE FORM BY USING ABSORBANCE RATIO METHOD}

\section{Preparation of Standard Stock Solutions of SAC and VAL:}

$100 \mathrm{mg}$ of Sacubitril (SAC) and $100 \mathrm{mg}$ of Valsartan (VAL) were measured separately and transferred to two separate volumetric bottles. Each drug was dissolved in $60 \mathrm{ml}$ of methanol and shaken by hand for 10 minutes. The dose was applied to the mark with distilled water and the final strength obtained was $1000 \mu \mathrm{g} / \mathrm{ml}$.

\section{Determination of » $\max$ :}

From the stock solutions, $.1 \mathrm{ml}$ of SAC and $.1 \mathrm{ml}$ of VAL was transferred to two separate $10 \mathrm{ml}$ volumetric flasks and the volume was adjusted to the mark with solvent ( methanol: water, 60:40) i.e. strength obtained was $10 \mu \mathrm{g} / \mathrm{ml}$ for SAC and 10 $\mu \mathrm{g} / \mathrm{ml}$ for VAL. Both the drug solutions were scanned separately between $200 \mathrm{~nm}$ to $400 \mathrm{~nm}$. The overlain spectrum of both drugs was recorded (Shown in Fig 8) and two wavelengths $240.0 \mathrm{~nm}$ (isoabsorptive point) and 254.0 nm (» max of VAL) were selected for estimation of drugs using absorbance ratio method.

\section{Study of Linearity for SAC:}

Appropriate known volumes of aliquots from standard SAC stock solution were transferred to five separate volumetric flasks of capacity $10 \mathrm{ml}$ each. The volume was changed to a mark with the solvent Methanol: Water (60:40) to determine the 4, 6, 8, 10, and 12; $\mu \mathrm{g} / \mathrm{ml}$. Absorbance $\mathrm{s}$ of these solutions were recorded at $240.0 \mathrm{~nm}$ and $254 \mathrm{~nm}$. (Shown in Tables 12 and

\section{Table}

- $\quad$ and the Calibration curve were plotted, absorbance vs concentration (shown in Fig. 9and Fig. 10).

Table No: 12. Linearity study of SAC at $240.0 \mathrm{~nm}$

\begin{tabular}{|l|l|l|l|}
\hline Sr.No. & $\begin{array}{l}\text { Concentration of } \\
\text { SAC in }(\mu \mathrm{g} / \mathrm{ml})\end{array}$ & $\begin{array}{c}\text { Absorbance Mean } \\
\pm \text { SD }(\mathrm{n}=5)\end{array}$ & \% RSD \\
\hline 1 & 4 & $\mathbf{0 . 1 6 0} \pm \mathbf{0 . 0 0 1 4}$ & $\mathbf{0 . 8 8}$ \\
\hline 2 & 6 & $0.238 \pm 0.0014$ & 0.59 \\
\hline 3 & 8 & $0.313 \pm 0.002$ & 0.63 \\
\hline
\end{tabular}




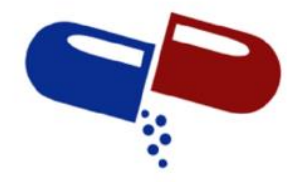

IJPSM

Kumrawat Kajal et al, International Journal of Pharmaceutical Sciences and Medicine (IJPSM), Vol.7 Issue. 1, January- 2022, pg. 1-23

ISSN: 2519-9889

Impact Factor: 5.365

\begin{tabular}{|l|l|l|l|}
\hline 4 & 10 & $0.396 \pm 0.0014$ & 0.35 \\
\hline 5 & 12 & $0.476 \pm 0.0014$ & 0.29 \\
\hline
\end{tabular}

Table No: 13. Linearity study of SAC at $254.0 \mathrm{~nm}$.

\begin{tabular}{|l|ll|l|l|}
\hline Sr.No. & \multicolumn{2}{|l|}{ Concentration of } & Absorbance Mean & \% RSD \\
& SAC in $(\mu \mathrm{g} / \mathrm{ml})$ & \pm SD $(\mathrm{n}=5)$ & \\
\hline 1 & 4 & $\mathbf{0 . 1 6 0} \pm \mathbf{0 . 0 0 1 3}$ & 0.80 \\
\hline 2 & 6 & $0.242 \pm 0.0011$ & 0.47 \\
\hline 3 & 8 & $0.324 \pm 0.0011$ & 0.35 \\
\hline 4 & 10 & $0.400 \pm 0.0012$ & 0.28 \\
\hline 5 & 12 & $0.483 \pm 0.0013$ & 0.27 \\
\hline
\end{tabular}

Study of Linearity for VAL:

Appropriate known volumes of aliquots from standard VAL stock solution were transferred to five separate volumetric flasks of capacity $10 \mathrm{ml}$ each.

The volume was changed to a mark with the solvent Methanol: Water (60:40) to determine the 4, 6, 8, 10, and 12; $\mu \mathrm{g}$ / ml. Absorbance s of these solutions were recorded at $240.0 \mathrm{~nm}$ and $254 \mathrm{~nm}$. (Table 14 and Table 15) and the calibration curve were plotted, absorbance $V s$ concentration (shown in Fig. 11 and Fig. 12)

Table No: 14. Linearity study of VAL at $240.0 \mathrm{~nm}$

\begin{tabular}{|l|l|l|l|}
\hline Sr.No. & $\begin{array}{l}\text { Concentration of } \\
\text { VAL in }(\mu \mathrm{gg} / \mathrm{ml})\end{array}$ & $\begin{array}{l}\text { Absorbance Mean } \\
\pm \text { SD }(\mathrm{n}=5)\end{array}$ & \% RSD \\
\hline 1 & 2 & $0.092 \pm 0.0014$ & 1.72 \\
\hline 2 & 4 & $0.163 \pm 0.0028$ & 1.73 \\
\hline 3 & 6 & $0.243 \pm 0.0012$ & 0.52 \\
\hline 4 & 8 & $0.327 \pm 0.0010$ & 0.33 \\
\hline 5 & 10 & $0.408 \pm 0.0006$ & 0.15 \\
\hline
\end{tabular}




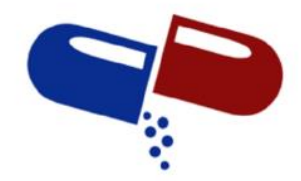

IJPSM

Kumrawat Kajal et al, International Journal of Pharmaceutical Sciences and Medicine (IJPSM), Vol.7 Issue. 1, January- 2022, pg. 1-23

ISSN: 2519-9889

Impact Factor: 5.365

Table No: 15. Linearity study of VAL at $254.0 \mathrm{~nm}$.

\begin{tabular}{|l|l|l|l|}
\hline Sr.No. & $\begin{array}{l}\text { Concentration of } \\
\text { VAL in }(\mu \mathrm{g} / \mathrm{ml})\end{array}$ & $\begin{array}{l}\text { Absorbance Mean } \\
\pm \mathrm{SD} \quad(\mathrm{n}=5)\end{array}$ & \\
\hline 1 & 2 & $\mathbf{0 . 2 2 4} \pm \mathbf{0 . 0 0 2 0}$ & 0.92 \\
\hline 2 & 4 & $0.448 \pm 0.0019$ & 0.43 \\
\hline 3 & 6 & $0.672 \pm 0.0020$ & 0.30 \\
\hline 4 & 8 & $0.889 \pm 0.0019$ & 0.21 \\
\hline 5 & 10 & $1.099 \pm 0.0019$ & 0.17 \\
\hline
\end{tabular}

Determination of Absorptivity values of drugs at selected wavelengths:

Absorptivity values of SAC and VAL were calculated by using following formula :- a $(1 \%, 1 \mathrm{~cm})=\mathrm{A} / \mathrm{C}$

$\mathrm{L}$

Where,

$\mathrm{a}=$ absorptivity,

A = absorbance,

$\mathrm{C}=$ concentration $\mathrm{gm} / 100 \mathrm{ml}$

, $\mathrm{L}=$ path length

Results of absorptivity values of drugs are shown in Table 16.

Table No: 16. Absorptivity Values of SAC and VAL at $240.0 \mathrm{~nm}$ and $254.0 \mathrm{~nm}$

\begin{tabular}{|l|l|l|l|l|}
\hline Sr.No. & \multicolumn{2}{|l|}{ Absorptivity at 240.0 nm } & \multicolumn{2}{l|}{ Absorptivity at 254.0 nm } \\
\hline & SAC & VAL & SAC & VAL \\
\hline 1 & 395.0 & 410.0 & 400.0 & 1120.0 \\
\hline 2 & 400.0 & 407.5 & 403.3 & 1120.0 \\
\hline 3 & 396.66 & 405.0 & 405.0 & 1120.0 \\
\hline 4 & 391.25 & 408.75 & 409.0 & 1111.25 \\
\hline 5 & 396 & 408.0 & 402.5 & 1099.0 \\
\hline Mean & ax1=395.92 & ax2=408.34 & ay1 $=404.13$ & ay2=1107.40 \\
\hline
\end{tabular}

The concentration of two drugs in the mixture can be calculated by using equations $\mathrm{CSAC}=\mathrm{QM}$

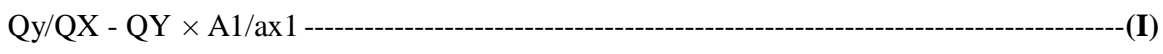

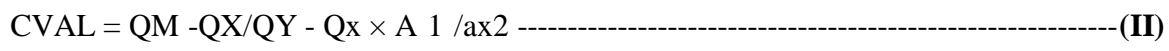




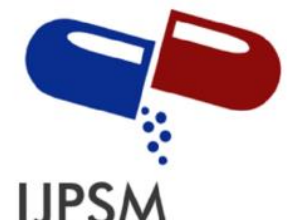

Kumrawat Kajal et al, International Journal of Pharmaceutical Sciences and Medicine (IJPSM), Vol.7 Issue. 1, January- 2022, pg. 1-23

ISSN: 2519-9889

Impact Factor: 5.365

Where, A1 is absorbance of mixture at 240nm (isoabsorptive point) and ax1 (395.92), ax2 (408.34) and ay1 (404.13), ay2 (1107.40) are absorptivity of SAC and VAL at 240nm and 254nm respectively and QM = A2/A1, QY = ay2/ay1 and $\mathrm{QX}=\operatorname{ax} 2 / \mathrm{ax} 1$.

\section{- Laboratory mixture analysis by proposed method:}

In order to demonstrate the concurrence of the proposed simultaneous evaluation of SAC and VAL in the development of manufactured drugs, this approach was first attempted to balance drugs in a standard laboratory association.

A well-balanced dose of $100 \mathrm{mg}$ SAC and $100 \mathrm{mg}$ VAL was taken in a $100 \mathrm{ml}$ volumetric bottle and dissolved in 60 $\mathrm{ml}$ of Methanol by vigorous shaking. The volume is built into the tag with the same water included. The aliquot portions of this stock solution were further diluted with solvent to get final concentration of SAC and VAL in ratio 4:8 and $6: 6 \mu \mathrm{g} / \mathrm{ml}$ respectively and the absorbance were measured at $240.0 \mathrm{~nm}$ and $254.0 \mathrm{~nm}$ against solvent as blank.

Amount of each drug was estimated using I, II equation as follows and results are reported in Table 17.

Table 17: Analysis of SAC and VAL in laboratory mixture:

\begin{tabular}{|l|l|l|l|l|c|}
\hline Sr.No. & $\begin{array}{l}\text { Amount Taken } \\
\mathrm{mg} / \mathrm{mL}\end{array}$ & $\begin{array}{l}\text { Amount found } \\
\mathrm{mg} / \mathrm{mL}\end{array}$ & Amount found (\%) & SD & $\begin{array}{c}\% \\
\text { RSD }\end{array}$ \\
\hline 1 & SAC 4 & 3.89 & 97.25 & $\mathbf{0 . 0 0 1 6}$ & $\mathbf{0 . 3 3}$ \\
\hline 2 & VAL 8 & 8.02 & 100.25 & $\mathbf{0 . 0 0 0 8}$ & $\mathbf{0 . 0 7}$ \\
\hline 3 & SAC 6 & 6.04 & 100.66 & $\mathbf{0 . 0 0 0 8}$ & $\mathbf{0 . 1 6}$ \\
\hline 4 & VAL 6 & $\mathbf{6 . 2 8}$ & $\mathbf{1 0 4 . 6 6}$ & $\mathbf{0 . 0 0 1 6}$ & $\mathbf{0 . 1 7}$ \\
\hline
\end{tabular}

* No.of three estimations

\section{- Application of Proposed Method For Analysis of tablet Formulation :}

Twenty tablets were weighed and crushed to obtain a fine powder. An accurately weighed sample equivalent to 100 $\mathrm{mg}$ of SAC and $100 \mathrm{mg}$ of VAL was taken in a stoppered volumetric flask $(100.0 \mathrm{ml}) ; 60 \mathrm{ml}$ of Methanol was added and sonicated for $10 \mathrm{~min}$. The solution is filtered through Whatmann's filter paper (No. 41) and the volume is applied to the mark with distilled water. The aliquot components of the above solutions were then diluted with solvent to obtain a final concentration of about $6(\mathrm{~g} / \mathrm{ml} \mathrm{SAC}$ and $6(\mathrm{~g} / \mathrm{ml}$ of VAL, respectively and the reductions were measured at $240.0 \mathrm{~nm}$ and $254.0 \mathrm{~nm}$ in the negative. the drugs in the sample were determined using statistics I and II.The results are reported in Table 18 


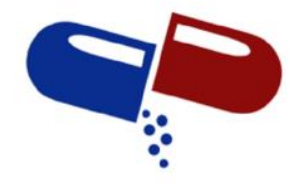

IJPSM

Kumrawat Kajal et al, International Journal of Pharmaceutical Sciences and Medicine (IJPSM), Vol.7 Issue. 1, January- 2022, pg. 1-23

ISSN: 2519-9889

Impact Factor: $\mathbf{5 . 3 6 5}$

Table 18: Application of Proposed Method for Analysis of Tablets

\begin{tabular}{|c|l|c|c|c|}
\hline Sample & Label claimed & \% Label claim & * S.D & \% RSD \\
\hline \multirow{2}{*}{1} & SAC 24mg & 95.16 & .0006 & 0.17 \\
& VAL 26mg & 102.83 & .0024 & 0.26 \\
\hline
\end{tabular}

* Mean of three observations

- Validation of Proposed method: The Proposed method was validated as per the ICH guidelines.

- Accuracy :

- To assess the accuracy of the improved methods and to study the deformity of structural additives, the analytical recovery tests are performed in a standard add-on. The recovery study was performed by adding 80, 100 and $120 \%$ of the test torture according to the ICH guidelines. The known amount of drug added to the preanalyzed tablet powder $6 \mu \mathrm{g} /$ $\mathrm{ml}$ of SAC and $6 \mu \mathrm{g} / \mathrm{ml}$ of VAL and the percentage return is calculated. The results and statistics for SAC and VAL are reported in Table 19.

Table 19: Recovery Study Data

\begin{tabular}{|l|l|l|l|l|}
\hline Sr.No. & \multicolumn{2}{|l|}{ Concentration of Drug Added $(\boldsymbol{\mu g} / \mathbf{m L})$} & \% Recovery \pm SD \\
\hline & SAC & VAL & SAC & VAL \\
\hline $\mathbf{1}$ & 4.8 & 4.8 & $100.75 \pm 0.16$ & $104.53 \pm 0.16$ \\
\hline $\mathbf{2}$ & 6.0 & 6.0 & $100.02 \pm 0.16$ & $104.66 \pm 0.16$ \\
\hline $\mathbf{3}$ & 7.2 & 7.2 & $100.68 \pm 0.16$ & $104.62 \pm 0.16$ \\
\hline
\end{tabular}

* Mean of three observations

\section{- Precision:}

- Precision is determined by intra-day and inter-day precision. Intra-day precision was determined by analyzing the 4,6 , $8,1 / 4 \mathrm{~g} / \mathrm{mL}$ of SAC and $2,4,61 / 4 \mathrm{~g} / \mathrm{mL}$ of VAL of drug solutions for three times in the same day.

Inter-day precision was determined by analyzing the $4,6,8,1 / 4 \mathrm{~g} / \mathrm{mL}$ of SAC and $2,4,61 / 4 \mathrm{~g} / \mathrm{mL}$ of VAL of drug solutions daily for three days, results are reported in Table $\mathbf{2 0 .}$

Table 20 : Intraday and Interday precision

\begin{tabular}{|c|c|c|c|c|c|c|}
\hline SR.NO & Drug & Conc. & Intraday* & \%RSD & Interday * & \% RSD \\
\hline & & $4.0 \mu \mathrm{g} / \mathrm{ml}$ & 3.97 & 0.54 & 4.08 & 0.87 \\
\hline \multirow[t]{4}{*}{1} & SAC & $6.0 \mu \mathrm{g} / \mathrm{ml}$ & 5.99 & 0.39 & 6.02 & 0.35 \\
\hline & & $8.0 \mu \mathrm{g} / \mathrm{ml}$ & 8.05 & 0.67 & 7.96 & 0.64 \\
\hline & & $2.0 \mu \mathrm{g} / \mathrm{ml}$ & 2.01 & 0.36 & 1.92 & 0.74 \\
\hline & & $4.0 \mu \mathrm{g} / \mathrm{ml}$ & 3.98 & 0.36 & 4.02 & 0.36 \\
\hline \multirow[t]{2}{*}{2} & VAL & & & & & \\
\hline & & $6.0 \mu \mathrm{g} / \mathrm{ml}$ & 6.03 & 0.24 & 6.07 & 0.25 \\
\hline
\end{tabular}

*Mean of three observations 


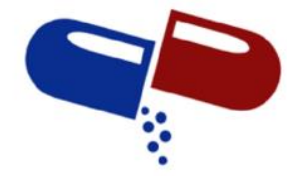

IJPSM

Kumrawat Kajal et al, International Journal of Pharmaceutical Sciences and Medicine (IJPSM), Vol.7 Issue. 1, January- 2022, pg. 1-23

ISSN: 2519-9889

Impact Factor: 5.365

\section{- Repeatibility:}

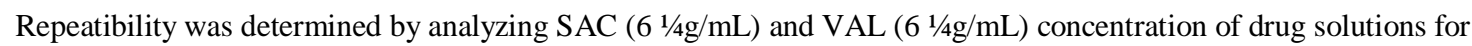
five times and results are reported in Table 21

Table 21: Repeatibility data

\begin{tabular}{|l|l|l|l|l|}
\hline Sr.No & Drug & $\begin{array}{l}\text { Amount taken* } \\
(\boldsymbol{\mu g} / \mathbf{m L})\end{array}$ & $\begin{array}{l}\text { Amount found } \\
(\boldsymbol{\mu g} / \mathbf{m L})\end{array}$ & $\%$ RSD \\
\hline 1 & SAC & 6 & 6.06 & 0.65 \\
\hline 2 & VAL & 6 & 6.27 & 0.30 \\
\hline
\end{tabular}

*Mean of five observations

\section{- Ruggedness:}

Ruggedness of the proposed method is determined by analysis of aliquots from homogenous slot by two analyst using same operational and environmental conditions and the results are reported in Table 22

Table 22: Ruggedness Data

\begin{tabular}{|l|l|l|l|l|l|}
\hline Drug & Amount taken $(\mu \mathrm{g} / \mathrm{ml})$ & Analyst I* & \% RSD & Analyst II * & \% RSD \\
\hline SAC & 6.0 & 5.97 & 0.65 & 6.16 & 0.61 \\
\hline VAL & 6.0 & 6.05 & 0.30 & 6.25 & 0.23 \\
\hline
\end{tabular}

*Mean of five estimation

\section{- Linearity}

For each drug, appriote dilutions of standard stock solution were assayed as per the developed method.The Beer s Lambert s concentration range was found to be $4-20 \mathrm{mg} / \mathrm{ml}$ for SAC and $2-10 \mathrm{mg} / \mathrm{ml}$ for VAL at their respective selected wavelengths. Coefficient of correlation was found to be 0.9997 for SAC and 0.9998 for VAL.

\section{RESULT \& DISCUSSION}

\section{METHOD - I}

UV-Spectrophotometric Method for Estimation of Sacubitril and Valsartanin Bulk and Tablet Dosage Form by Simultaneous Equation Method.

UV-spectrophotometric method using simultaneous equation was developed. SAC showed absorbance maxima at $226 \mathrm{~nm}$ and VAL at $254.0 \mathrm{~nm}$. Linearity was observed in the concentration rage of $4-20 \mu \mathrm{g} / \mathrm{ml}$ for SAC and $2-10 \mu \mathrm{g} / \mathrm{ml}$ for VAL. The proposed method was applied for pharmaceutical formulation and \% label claim for SAC and VAL was found to be 97.00 and 102.20, respectively. The recovery studies were carried out at 80, 100, $120 \%$ level and \% recovery for SAC 


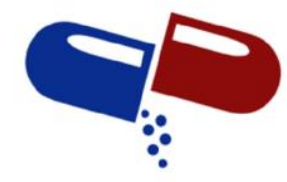

IJPSM

Kumrawat Kajal et al, International Journal of Pharmaceutical Sciences and Medicine (IJPSM), Vol.7 Issue. 1, January- 2022, pg. 1-23

ISSN: 2519-9889

Impact Factor: 5.365

and VAL was found to be 96.6897 .22 and 101.89-102.22, respectively. The low \% RSD indicates the method is accurate and precise and can be used for routine pharmaceutical analysis.

\section{Summary of Validation Parameter}

Parameters SAC VAL
Recovery $(\mathbf{n}=3)$
96.6897 .22
101.89102 .22

Precision (\% RSD)

Intra-day $(n=3)$

$0.48-0.65$

$0.24-0.36$

Inter-day $(\mathrm{n}=3)$

$0.48-0.98$

$0.25-0.74$

Repeatibility ( $\mathrm{n}=5)$

0.65

0.30

Ruggedness (\% RSD)

Analyst 1

0.65

0.30

Analyst 2

0.61

0.23

\section{METHOD - II}

UV-Spectrophotometric Method for Simultaneous Estimation of Sacubitril and Valsartan in Bulk and Tablet Dosage Form by Absorbance ratio method.

UV-spectrophotometric method by using absorbance ratio method was developed. Absorbance selected were $240 \mathrm{~nm}$ (isoabsorptive point) and $254 \mathrm{~nm}$ (» max of Valsartan) Linearity was observed in the concentration range of 4 - 20 $\mu \mathrm{g} / \mathrm{mland} 2-10 \mu \mathrm{g} / \mathrm{ml}$. The proposed method was applied for pharmaceutical formulation; $\%$ label claim for SACandVAL was found to be $\mathbf{9 5 . 1 6}$ and 102.83, respectively. The recovery studies were carried out at 80, 100, $120 \%$ level and \% recovery for SAC and VAL was found to be $100.02-100.75$ and 104.53104 .66 , respectively.

Summary of Validation Parameters

\begin{tabular}{|l|l|l|}
\hline Parameters & \multicolumn{1}{|c|}{ SAC } & VAL \\
\hline Recovery (n=3) & $100.02-100.75$ & $104.53-104.66$ \\
\hline Precision (\% RSD) & $0.39-0.67$ & $0.35-0.87$ \\
\hline Intra-day (n=3) & $0.24-0.36$ & $0.25-0.74$ \\
\hline Inter-day (n=3) & 0.65 & 0.30 \\
\hline Repeatibility (n=5) & 0.65 & 0.30 \\
\hline Ruggedness (\% RSD) & 0.23 & 0.61 \\
\hline Analyst 1 & \\
\hline Analyst 2 &
\end{tabular}




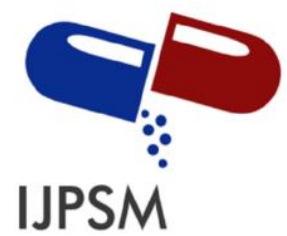

\section{Kumrawat Kajal et al, International Journal of Pharmaceutical Sciences and Medicine (IJPSM), Vol.7 Issue. 1, January- 2022, pg. 1-23}

ISSN: 2519-9889

Impact Factor: 5.365

\section{CONCLUSIONS}

Spectroscopy is one of the most widely used technique to carry out the analysis of pharmaceutical preparation. UV spectroscopy is based on the measurement of spectrum of sample contains atom. A broad range of techniques are available for the analysis of sacubitril and valsartan in pharmaceutical formulation. These techniques are very useful in the structure elucidation of organic molecule.

In the research work done, a successful attempt for simultaneous analysis of SAC and VAL in tablet formulation by following spectrophotometric methods was made by experimentation based on through literature survey. The spectrophotometric methods developed are:

- Simultaneous Equation Method.

- $\quad$ Absorbance Ratio Method.

- Multicomponent Mode Method.

The simplicity, rapidity, reproducibility, and repeatability of the proposed methods completely fulfill the objective of the research work of simultaneous analysis of this drug combination.

\section{METHOD 1}

UV-spectrophotometric method using simultaneous equation was developed. SAC showed absorbance maxima at $226 \mathrm{~nm}$ and VAL at $254.0 \mathrm{~nm}$. Linearity was observed in the concentration rage of $4-20 \mu \mathrm{g} / \mathrm{ml}$ for SAC and $2-10 \mu \mathrm{g} / \mathrm{ml}$ for VAL. The proposed method was applied for pharmaceutical formulation and \% label claim for SAC and VAL was found to be 97.00 and 102.20, respectively. The recovery studies were carried out at 80,100, $120 \%$ level and \% recovery for SAC and VAL was found to be 96.6897 .22 and 101.89-102.22, respectively. The low \% RSD indicates the method is accurate and precise and can be used for routine pharmaceutical analysis.

\section{METHOD 2}

UV-spectrophotometric method using simultaneous equation was developed. SAC showed absorbance maxima at $226 \mathrm{~nm}$ and VAL at $254.0 \mathrm{~nm}$. Linearity was observed in the concentration rage of $4-20 \mu \mathrm{g} / \mathrm{ml}$ for SAC and $2-10 \mu \mathrm{g} / \mathrm{ml} \mathrm{for} \mathrm{VAL}$. The proposed method was applied for pharmaceutical formulation and \% label claim for SAC and VAL was found to be 97.00 and 102 .20 , respectively. The recovery studies were carried out at 80,100, $120 \%$ level and \% recovery for SAC and VAL was found to be 96.6897 .22 and 101.89-102.22, respectively. The low \% RSD indicates the method is accurate and precise and can be used for routine pharmaceutical analysis.

ANALYTIK JENA- SPECORD 210 PLUS UV-Visible double beam recording spectrophotometer was employed for analysis. Simultaneous analysis of SAC and VAL was performed in Methanol. Both the drugs followed beers law in the concentration range utilized during analysis.

All the methods were validated as per ICH norms.

It can be said that above three methods can be used for routine laboratory analysis with precision and accuracy.

\section{REFERENCES}

[1]. Simultaneous estimation of multicomponent formulations by UV-visible spectroscopy: an overview. Chaudhary J, Jain A, Saini V. 2011, International Journal of Pharmacy, pp. 81-83.

[2]. Boylan JC, Swarbrick J. Encyclopedia of pharmaceutical technology. [book auth.] Marcel Dekker. 1998, pp. $217-224$.

[3]. Beckette AH, Stenlake JB. Practical Pharmaceutical Chemistry, Part I. New Delhi : CBS Publishers and Distributors, 1997.

[4]. Lachman L, Herbert A, Lieberman, Kanig JL. The theory and practice of industrial. Bombay: Varghese publishing house, 1987.

[5]. Advances in hydrotropic solutions: an updated review. Dhapte V, Mehta P. 2015, St. Petersburg Polytechnical University Journal: Physics and Mathematics, pp. 424-435.

[6]. Hydrotropic Solubilization: Tool for Eco-Friendly Analysis. Ghogare D, Patil S. 2018, International Jour of Pharmacy and Pharmaceutical Research, pp. 300-322. 


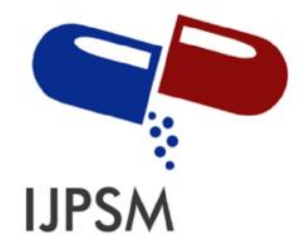

Kumrawat Kajal et al, International Journal of Pharmaceutical Sciences and Medicine (IJPSM), Vol.7 Issue. 1, January- 2022, pg. 1-23

ISSN: 2519-9889

Impact Factor: 5.365

[7]. New spectrophotometric determination of hydrochlorothiazide in tablets using mixed hydrotropic solubilization technique. Maheshwari RK, Rajput MS, Sharma S, Nair V. 2010, Der Pharmacia Lettre, pp. 70-74.

[8]. New method development and validation for the simultaneous estimation of sacubitril and valsartan in a bulk and pharmaceutical dosage forms. Vaka S, Parthiban P. 2017, Int J Res, pp. 17-24.

[9]. Simultaneous estimation of sacubitril and valsartan in synthetic mixture by RP-HPLC method. Patel KH, Luhar SV, Narkhede SB.2016, J Pharm Sci Bioscientific Res, pp. 262-269.

[10].Application of TLC-Densitometric Method for Simultaneous Determination of Sacubitril and Valsartan in their Newly Approved Pharmaceutical Formulation. Attia KA, Nassar MW, El-Olemy A, Ramzy S. 2018, Eurasian Journal of Analytical Chemistry, pp. 67- 75.

[11].ANALYTICAL METHODOLOGIES FOR DETERMINATION OF VALSARTAN: AN OVERVIEW. Sivakamasundari G, Kannappan N. 2017, World Journal of Pharmacy and Pharmaceutical Sciences, pp. 605-617.

[12].Sacubitril/valsartan: A novel angiotensin receptor-neprilysin inhibitor. Dargad RR, Prajapati MR, Dargad RR, Parekh JD. 2018, Indian heart journal, pp. 102-110.

\section{A Brief Author Biography}

Kajal Kumrawat - Ms. Kajal Kumrawat, has obtained her B. Pharma. from Swami Vivekanand college of Pharmacy, Indore, M.P., India, and presently pursuing M. Pharma. from Swami Vivekanand college of Pharmacy, Indore, M.P. India. Her keen interest is in analytical pharmacology, and medicinal chemistry.

Archana Dubey Tiwari - Mrs. Archana Dubey Tiwari, has obtained her B.pharma Swami Vivekananda College Of Pharmacy, Khandwa Road, Indore, M.P. India M.pharma (pharmaceutical chemistry), with Hons from Swami Vivekananda College Of Pharmacy, Khandwa Road, Indore, M.P. India, Phd pursuing from sage university, indore M.P. She is presently working us associated Professor, department of pharmaceutical chemistry Swami Vivekananda College Of Pharmacy, Khandwa Road, Indore, her keen interest organic chemistry, biochemistry, pharmaceutical analysis and medicinal chemistry. 